\title{
ANALISIS PERANGKAT LUNAK PENILAIAN DIGITAL PERTANDINGAN PENCAK SILAT MENGGUNAKAN ISO 9126
}

\author{
Reza Prasetyo Aji ${ }^{1}$ \\ Program Studi Teknik Informatika, Universitas Indraprasta PGRI \\ rezaprasetyo801@gmail.com
}

Submitted October 23, 2020; Revised March 21, 2021; Accepted March 24, 2021

\begin{abstract}
Abstrak
Penelitian ini bertujuan (1) untuk mengetahui aplikasi eventsilat.com memiliki kualitas perangkat lunak yang baik atau tidak menurut ISO 9126, (2) untuk mengetahui cara mengukur karakteristik kualitas functionality, reliability, usability, efficiency, maintainability, dan portability pada aplikasi eventsilat.com dan (3) untuk mengetahui kualitas dari hasil akhir functionality, reliability, usability, efficiency, maintainability, dan portability pada aplikasi eventsilat.com berdasarkan ISO 9126. Analisis dilakukan melalui uji kasus (test case) dari setiap karakteristik ISO 9126. Hasil penelitian ini menunjukan(1) aplikasi penilaian digital eventsilat.com secara keseluruhan memperoleh interprestasi baik menurut ISO 9126 dengan nilai 3,09 (2). Cara mengukur karakteristik kualitas functionality, reliability, usability, efficiency, maintainability, dan portability pada aplikasi eventsilat.comadalah dengan mengukur nilai interprestasi menggunakan skala likert dari setiap karakter dan sub karakter ISO 9126 dan selanjutnya dilakukan uji kasus (test case) dan (3) kualitas dari hasil akhir functionality adalah sangat baik dengan nilai 3,26, kualitas reliability adalah baik dengan nilai 2,74, kualitas usability adalah sangat baik dengan nilai 3,52, kualitas efficiency adalah baik dengan nilai 2,91, kualitas maintainability adalah baik dengan nilai 2,99 , dan kualitas portability adalah baik dengan nilai 3,09.
\end{abstract}

Kata Kunci : Aplikasi Penilaian Digital, Eventsilat.com, ISO 9126

\begin{abstract}
This study aims (1) to know the quality of software possessed by eventsilat.com aplications, which is good or bad according to ISO 9126, (2) to know how to measure the quality characteristics of functionality, reliability, usability, efficiency, maintainability, and portability on eventsilat.com applications and (3) to know the quality of the last result of functionality, reliability, usability, efficiency, maintainability, and portability on eventsilat.com aplications based on ISO 9126. The analysis was conducted through a test case of each ISO 9126 characteristic. The results of this study show (1) the eventsilat.com digital assessment applications as a whole get good interpretation according to ISO 9126 with a value of 3.09 (2) How to measure the quality characteristics of functionality, reliability, usability, efficiency, maintainability, and portability at eventsilat.com aplications is by measuring the interpretation value using Likert scale of each character and sub character ISO 9126 and then test case, and (3) the quality of the last result of functionality is very good with the value of 3,26, the quality of reliability is good with a value of 2.74 , usability quality is very good with a value of 3.52, the quality of efficiency is good with a value of 2.91, the quality of maintainability is good with a value of 2.99, and quality portability is good with value of 3.09.
\end{abstract}

Key Words: Digital Assessment Applications, Eventsilat.com, ISO 9126

\section{PENDAHULUAN}

Pencak silat merupakan salah satu cabang olahraga yang juga mengikuti perkembangan teknologi. Hal ini membuat pencak silat harus terus meng-upgrade diri untuk diakui eksistensinya. Salah satu cara pencak silat meng-upgrade diri dalam mengikuti perkembangan teknologi adalah mulai bergesernya sistem administrasi dari cara konvensional menjadi digital, termasuk dalam hal penyelenggaraan event kejuaraan pencak silat. Proses dari 
pendaftaran peserta event, klasifikasi peserta pertandingan, jadwal pertandingan, penilaian saat pertandingan sampai dengan pengumuman peserta juara yang sebelumnya menggunakan form kertas menjadi digital menggunakan sistem online.

Sebelumnya, proses pendaftaran peserta untuk mengikuti event kejuaraan pencak silat dilakukan manual dengan cara setiap kontingen datang ke tempat pendaftaran yang telah ditentukan oleh panitia penyelenggara event kejuaraan. Setiap kontingen mengisi form untuk peserta yang didaftarkan dan melampirkan persyaratan yang telah ditentukan oleh panitia. Adapun cara yang digunakan saat ini dalam proses pendaftaran, setiap kontingen cukup mendaftarkan kontingennya dengan cara membuat akun secara online. Setelah mendapat email konfirmasi dari admin untuk aktivasi, kontingen selanjutnya dapat login dan mengisi form online dan mengmeng-upload persyaratan yang telah ditentukan panitia penyelenggara event.

Pada saat pertandingan sebelum adanya sistem digitalisasi, juri yang bertugas memberikan nilai setiap peserta kejuaraan menuliskan poin pada formhardcopy yang disediakan panitia penyelenggara. Nilai yang diberikan juri tidak dapat dilihat real time oleh peserta kejuaraan maupun pelatih. Hal ini membuat pertandingan kurang transparan karena hanya juri yang mengetahui nilai yang diberikan saat itu. Setelah adanya sistem digitalisasi nilai yang diberikan juri dapat dilihat realtime pada big screen, karena dalam memberikan nilai kepada peserta juri hanya melakukan input pada aplikasi online.

Sistem digital yang mulai digunakan penyelenggara kejuaraan pencak silat tersebut salah satunya adalah eventsilat.com. Layanan yang diberikan mulai dari pendaftaran online peserta kejuaraan sampai dengan pengumuman peserta kejuaraan baik secara individual maupun kontingen.
Kemudahan yang dihadirkan aplikasi eventsilat.com juga perlu dilakukan pengukuran kualitas dalam rangka evaluasi sebuah perangkat lunak. Terdapat beberapa standar yang dapat digunakan dalam pengujian perangkat lunak, salah satunya adalah ISO 9126.

ISO 9126 dibuat oleh International Organization Standardization (ISO) dan International ElectrotechnicalCommision (IEC) yang diperkenalkan pertama kali pada tahun 1991 [1]. ISO/IEC 9126 merupakan standar untuk produk terutama software yang mencakup model kualitas dan metric. Dengan demikian dalam model software yang berkualitas akan diuraikan mengenai faktor-faktor mengenai taxonomi dari software yang berkualitas. Didalam standard ISO/IEC 9126 diuraikan secara umum karakteristik yang diuraikan menjadi subkarakteristik sebagai tolok ukur software, yang menjadi framework untuk mengevaluasi sebuah software [2]. Standar ini digunakan karena ISO 9126 telah diakui secara internasional. Adapun karakteristik kualitas internal dan eksternal dalam ISO 9126 terdiri dari enam karakteristik kualitas yaitu Functionality, Reliability, Usa\bility, Efficiency, Maintainability, dan Portability seperti pada Gambar 1 berikut ini [3].

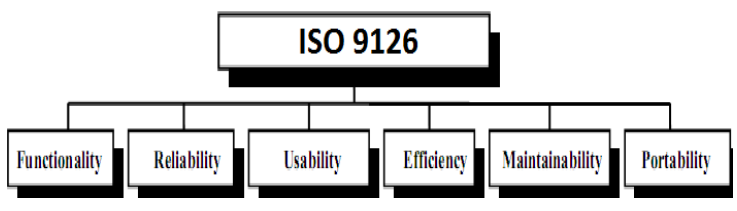

Gambar 1. Karakteristik ISO 9126

Dalam penelitian ini peneliti bermaksud untuk menguji dan melakukan penilaian kualitas terhadap aplikasi yang digunakan oleh eventsilat.com dalam melakukan penilaian pertandingan pencak silat dengan menggunakan standar ISO 9126. Sehingga hasil penelitian ini memberikan manfaat kepada eventsilat.com dalam 
pengembangan aplikasi yang digunakan kedepannya.

\section{METODE PENELITIAN}

Jenis Penelitian yang digunakan dalam penelitian ini adalah kuantitatif dengan objek penelitian adalah seluruh karyawan dari Eventsilat.com untuk pengujian alat (functinality) dan masyarakat pencaksilat seperti pelatih, ketua pertandingan serta wasit dan juri (usability).

Penelitian ini dilakukan di dua tempat, yaitu penelitan untuk tes aplikasi dan penelitian untuk penyebaran kuesioner terhadap pengguna aplikasi eventsilat.com. Penelitian untuk tes aplikasi dilakukan di kantor Eventsilat.com yang beralamat di jalan Dukuh, TMII, Jakarta Timur, Indonesia. Penelitian untuk penyebaran kuesioner dilakukan pada kejuaraan Gubernur Cup tahun 2017 yang dilaksanakan di GOR Ciracas yang beralamat di Jalan Raya Bogor KM. 25-26, Ciracas, RT.8/RW.8, Susukan, Kota Jakarta Timur, Daerah Khusus Ibukota Jakarta.

\section{HASIL DAN PEMBAHASAN}

\section{Analisis Sistem Berjalan Aplikasi}

Pada bagian ini bertujuan untuk mendapatkan gambaran umum berupa siapa saja pengguna dan fungsionalitas dari aplikasi yang nantinya akan digunakan sebagai acuan dalam membuat rancangan pengujian. Pada tahap Analisis Data, yang dilakukan adalah menganalisis sistem penilaian digital milik eventsilat.com. Adapun analisis ini hanya fokus pada sistem penilaian.

\section{a. Use Case Diagram}

Gambaran umum, perilaku, dan fungsionalitas dari aplikasi penilaian digital eventsilat.com digambarkan melalui diagram use case seperti pada Gambar 1.

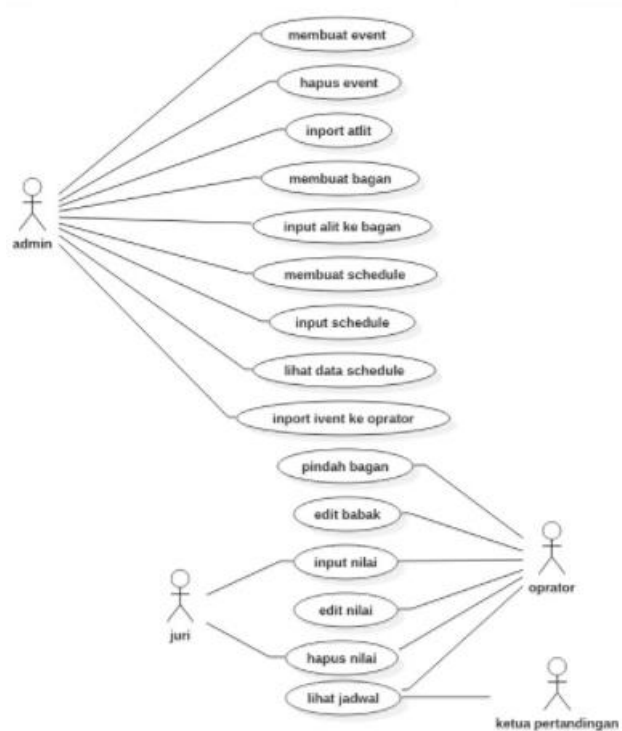

Gambar 2. Use Case Diagram penilaian digital

\section{b. Identifikasi Aktor}

Tabel 1. Indentifikasi Aktor

\begin{tabular}{|c|c|c|}
\hline No. & Aktor & Deskripsi \\
\hline 1. & $\begin{array}{l}\text { Ketua } \\
\text { Pertandingan }\end{array}$ & $\begin{array}{l}\text { Aktor hanya dapat melihat nilai } \\
\text { yang dimasukan oleh para juri dan } \\
\text { nama peserta yang sedang } \\
\text { bertanding. }\end{array}$ \\
\hline 2. & Juri & $\begin{array}{l}\text { Aktor yang dapat menginput nilai } \\
\text { point dan pinalty untuk peserta } \\
\text { yang sedang bertanding. }\end{array}$ \\
\hline 3 & Operator & $\begin{array}{l}\text { Aktor yang dapat login ke sistem, } \\
\text { untuk login ke aplikasi input data } \\
\text { untuk juri dan operator } \\
\text { pertandingan. }\end{array}$ \\
\hline 4 & Admin & $\begin{array}{l}\text { Aktor yang dapat login ke system, } \\
\text { membuat event, bagan, jadwal } \\
\text { pertandingan dan import data } \\
\text { peserta kedalam database system } \\
\text { penilaian. }\end{array}$ \\
\hline
\end{tabular}

\section{c. Diagram Aktivitas}

Diagram aktivitas atau activity diagram menggambarkan aliran kerja (workflow) atau aktivitas dari sebuah sistem atau proses bisnis atau menu yang ada pada perangkat lunak [4].

1) Activity Diagram untuk membuat Event Baru

Pada diagram aktivitas aktornya adalah admin. Admin melakukan login dan kemudian sistem akan melakukan validasi jika username dan password benar. Setelah proses login, akan tampil halaman utama 
dan menu. Pada menu, admin memilih menu pilih data management, lalu pilih event.Dalam menu event admin dapat menambah dan menghapus event. Untuk membuat event daru klik add data lalu isikan form yang ada di halaman add data, setelah itu kilk simpan data

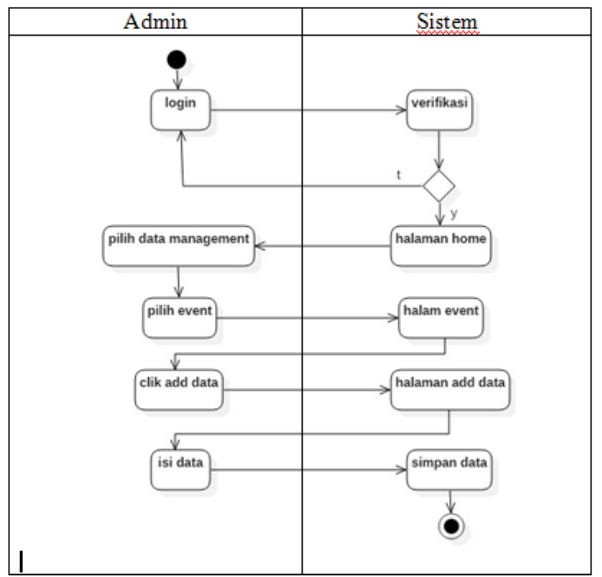

Gambar 3. Activity Diagram untuk membuat Event Baru

2) Activity Diagram untuk menghapus Event

Admin melakukan login dan kemudian sistem akan melakukan validasi jika username dan password benar. Setelah proses login, akan tampil halaman utama dan menu.

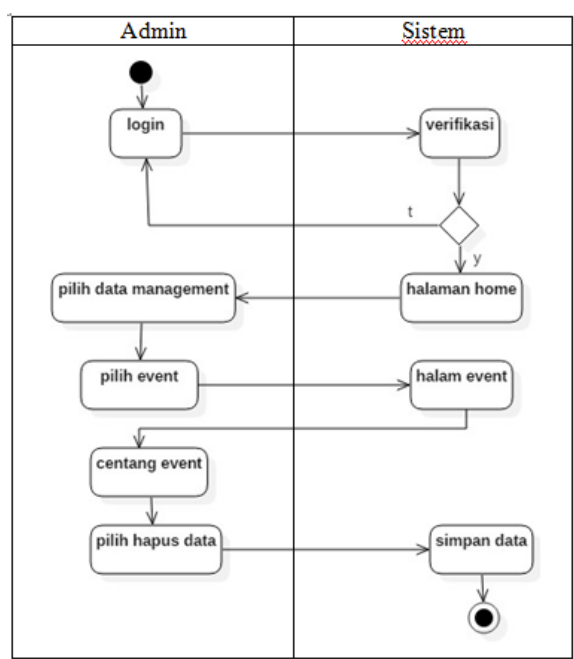

Gambar 4. Activity Diagram untuk menghapus Event
Pada menu, admin memilih menu pilih data management, lalu pilih event. Untuk menghapus event pilih event yang akan dihapus lalu pilih hapus data. Setelah selesai simpan data

3) Activity Diagram untuk Import Athlete Pada menu, admin memilih menu pilih operation lalu pilih import athlete.

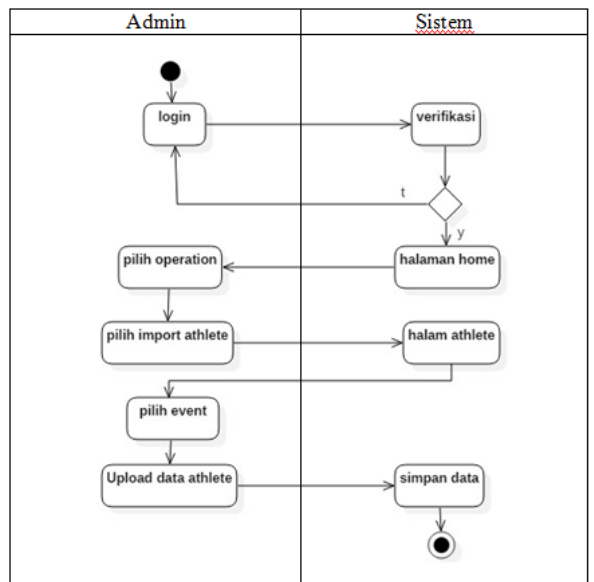

\section{Gambar 5. Activity Diagram untuk Import athlete}

Didalam halaman athlete admin pilih event yang akan di upload data athlete nya, lalu cari file athlete yang akan diupload. Setelah itu pilih simpan data.

4) Activity Diagram untuk lihat data Athlete

Setelah proses login, akan tampil halaman utama dan menu. Pada menu, pilih report lalu pilih athlete report.

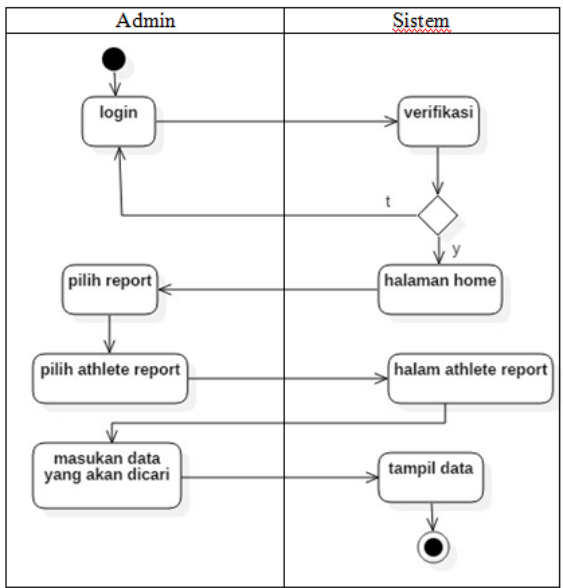

Gambar 6. Activity Diagram untuk Lihat data Athlete 
Didalam halam athlete report pilih show data untuk menampilkan seluruh data athlete atau isikan dan pilih beberapa filter untuk mencari lebih rinci.

\section{5) Activity Diagram untuk Generate Match Chart (Bagan)}

Setelah proses login, akan tampil halaman utama dan menu. Pada menu operation pilih Generate Match Chart.

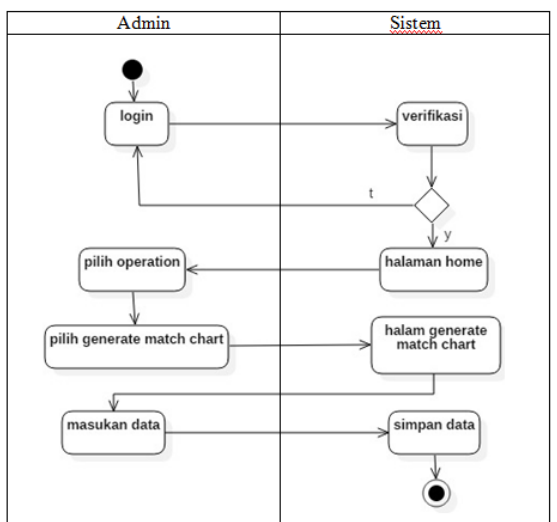

\section{Gambar 7. Activity Diagram untuk Generate Match Chart (Bagan)}

Didalam halaman Generate Match Chart masukan data untuk bagan lalu simpan data.

6) Activity Diagram untuk masukan athlete ke dalam Bagan

Setelah proses login, akan tampil halaman utama dan menu. Pada menu report pilih match chart report.

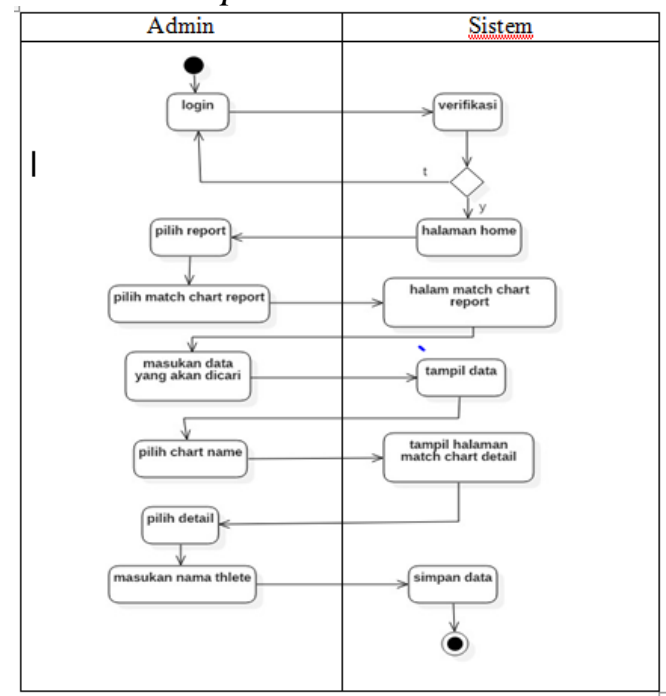

Gambar 8. Activity Diagram untuk masukan athlete ke dalam Bagan
Di halaman match chart report masukan data yang akan dicari, lalu pilih show data maka seluruh data akan ditampilkan. Pilih chart name lalu akan tampil halaman match chart secara detail. Masukan namaathlete kedalam bagan yang telah dibuat sebelumnya lalu simpan data.

7) Activity Diagram untuk Import Schedule

Setelah proses login, akan tampil halaman utama dan menu. Pada menu operation pilih import Schedule.

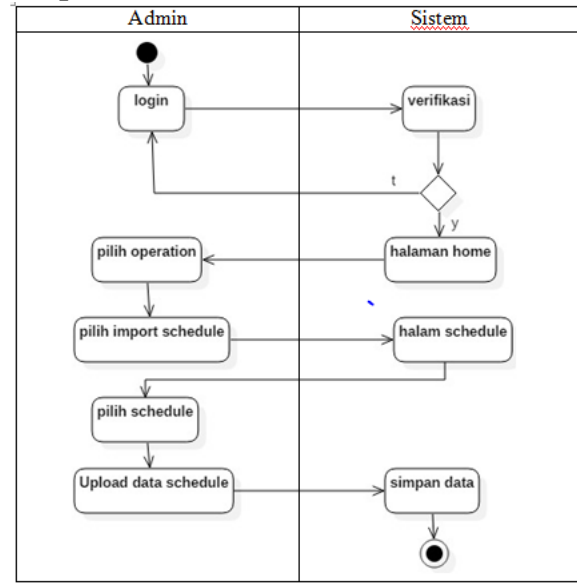

Gambar 9. Activity Diagram untuk Import Schedule

Didalam halaman Schedule admin pilih event yang akan di upload Schedule nya, lalu cari file Schedule yang akan diupload. Setelah itu pilih simpan data.

8) Activity Diagram untuk lihat data Schedule

Setelah proses login, akan tampil halaman utama dan menu. Pada menu, pilih report lalu pilih Schedule report. 


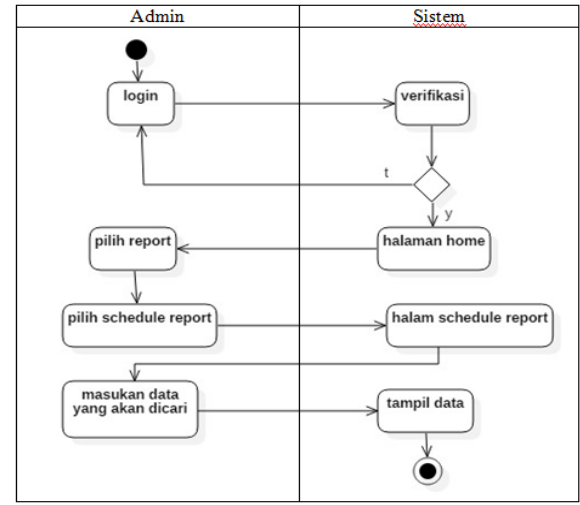

Gambar 10. Activity Diagram untuk lihat data Schedule

Didalam halam Schedule report pilih show data untuk menampilkan seluruh data athlete atau isikan dan pilih beberapa filter untuk mencari lebih rinci.

\section{9) Activity Diagram untuk Operator}

Operator melakukan login dan kemudian sistem akan melakukan sistem akan melakukan validasi jika username dan password benar. Setelah proses login, akan tampil halaman operator.

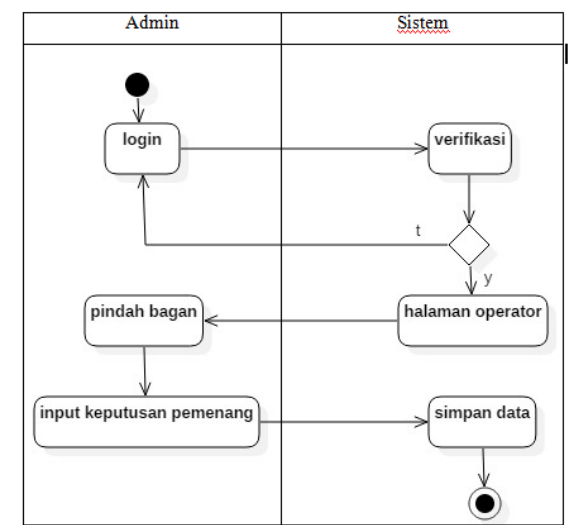

Gambar 11. Activity Diagram untuk Operator

Operator memindahkan bagan perjadwal dari satu atlit yang bertanding dan menginput keputusan pemenang lalu simpan data.

10) Activity Diagram untuk Penilaian Pada diagram aktivitas diatas aktornya adalah Juri. Admin melakukan login dan kemudian sistem akan melakukan validasi jika username dan password benar.

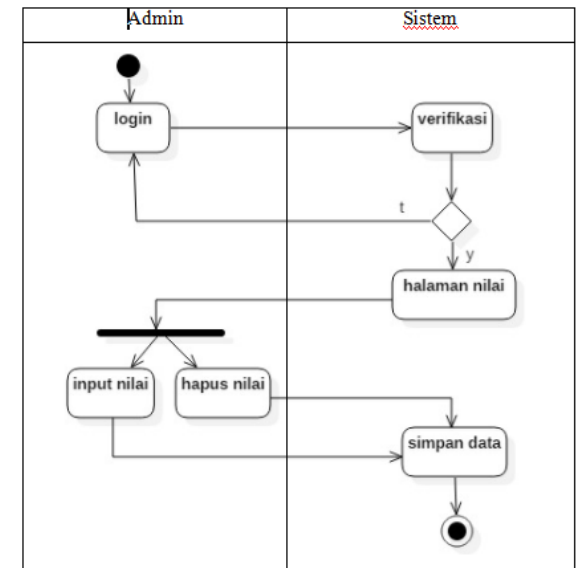

Gambar 12. Activity Diagram untuk Penilaian

Setelah proses login, akan tampil halaman input nilai. Pada halaman input nilai, juri menginput nilai dari setiap peserta yang sedang bertanding.

\section{Analisis Aplikasi berdasarkan ISO 9126}

Penelitian ini menggunakan 4 (empat) pilihan jawaban, mulai dari yang bermakna sangat negatif sampai yang bermakna positif dengan menggunakan skala likert [5].

$$
\mathrm{I}=\frac{\mathrm{R}}{\mathrm{K}}
$$

Dimana I adalah besarnya interval, $\mathrm{R}$ adalah jarak pengukuran dan $\mathrm{K}$ adalah jumlah kelas. Pada penelitian ini, nilai tertinggi adalah 4 (empat) dan nilai terendah adalah 1 (satu) dan jumlah kelas adalah 4 (empat). Maka, interval untuk penelitian ini adalah :

$$
I=\frac{(4-1)}{4}=\frac{3}{4}
$$

$$
\mathrm{I}=0,75
$$

Dengan demikian, dapat diketahui kualifikasi interprestasi jawaban responden untuk penelitian ini adalah sebagai berikut, 
Tabel 2. Kualifikasi Interpretasi

\begin{tabular}{cc}
\hline Range & Nilai Kualifikasi \\
\hline $3,26-4,00$ & Sangat Baik \\
$2,51-3,25$ & Baik \\
$1,76-2,50$ & Kurang Baik \\
$1,00-1,75$ & Buruk \\
\hline
\end{tabular}

Adapun kesimpulan atas hasil Pengujian Kuesioner Responden dapat dilihat pada tabel 3 di bawah ini :

\section{Tabel 3. Hasil Pengujian Kuesioner} Responden

\begin{tabular}{|c|c|c|c|}
\hline $\begin{array}{c}\text { Pengujian } \\
\text { Karakter }\end{array}$ & $\begin{array}{c}\text { Pengujian Sub } \\
\text { Karakter }\end{array}$ & $\begin{array}{c}\text { Nilai } \\
\text { Interpretasi }\end{array}$ & $\begin{array}{l}\text { Kualifikasi } \\
\text { Interpretasi }\end{array}$ \\
\hline \multirow{4}{*}{ Functionality } & Suitability & 3.43 & Sangat Baik \\
\hline & Accurateness & 3.35 & Sangat Baik \\
\hline & interoperability & 3.22 & Baik \\
\hline & Security & 3.04 & Baik \\
\hline \multicolumn{2}{|c|}{ Jumlah } & 3.26 & $\begin{array}{c}\text { Sangat } \\
\text { Baik }\end{array}$ \\
\hline \multirow{2}{*}{ Reliability } & Fault Tolerance & 2.78 & Baik \\
\hline & Recoverability & 2.70 & Baik \\
\hline \multicolumn{2}{|c|}{ Jumlah } & 2.74 & Baik \\
\hline \multirow{4}{*}{ Usability } & Understandability & 3.57 & Sangat Baik \\
\hline & Learnability & 3.61 & Sangat Baik \\
\hline & Operability & 3.48 & Sangat Baik \\
\hline & Attractiveness & 3.43 & Sangat Baik \\
\hline \multicolumn{2}{|c|}{ Jumlah } & 3.52 & $\begin{array}{c}\text { Sangat } \\
\text { Baik }\end{array}$ \\
\hline \multirow{3}{*}{ Efficiency } & Time Behavior & 2.87 & Baik \\
\hline & Resource & & \\
\hline \multirow{2}{*}{\multicolumn{2}{|c|}{ Jumlah }} & 2.96 & Baik \\
\hline & & & \\
\hline \multirow{4}{*}{ Maintainability } & Analysability & & Baik \\
\hline & Changeability & 3.17 & Sangat Baik \\
\hline & Stability & 2.96 & Baik \\
\hline & Testability & 3.09 & Baik \\
\hline \multicolumn{2}{|c|}{ Jumlah } & 2.99 & Baik \\
\hline Portability & Installability & 3.09 & Baik \\
\hline \multicolumn{2}{|c|}{ Jumlah } & 3.09 & Baik \\
\hline
\end{tabular}

Setelah memperoleh nilai dari setiap karakter ISO 9126 dalam menggunakan aplikasi eventsilat.com, dapat diketahui nilai interprestasi secara keseluruhan eventsilat.com berdasarkan ISO 9126. Adapun cara untuk mendapat nilai tersebut adalah sebagai berikut sebagaimana rumus untuk menghitung rata-rata [|6].

$$
\begin{aligned}
\text { Jumlah } & =\frac{(\text { Frekuensi } x \text { Bobot Nilai })}{\text { Jumlah Responden }} \\
& =\frac{\text { Nilai total }}{\text { Jumlah responden }}
\end{aligned}
$$

Nilai ISO 9126 Aplikasi Eventsilat.com :

$=\frac{\text { Total nilai kualifikasi karakter ISO } 9126}{\text { Jumlah karakter ISO } 9126}$

$=\frac{3,26+2,74+3,52+2,91+2,99+3,09}{6}$

$=3,09$

Mengacu pada tabel 2, secara keseluruhan aplikasi eventsilat.com memperoleh interprestasi Baik berdasarkan ISO 9126.

\section{SIMPULAN}

Aplikasi penilaian digital Eventsilat.com secara keseluruhan memperoleh interprestasi Baik dengan nilai 3,09 dengan menggunakan alat pengujian penyebaran kuesioner pada pengguna aplikasi. Hasil pengujian tingkat kualitas Functionality berdasarkan ISO 9126 adalah sangat baik dengan nilai interprestasi 3,26. Selanjutnya, tingkat kualitas Reliability adalah baik dengan nilai interprestasi 2,74. Kualitas Usability adalah sangat baik dengan nilai interprestasi 3,52. Tingkat kulitas Efficiency adalah baik dengan nilai interprestasi 2,91. Selanjutnya, kulitas Maintainability adalah baik dengan nilai interprestasi 2,99. Terakhir, tingkat kualitas Portability adalah baik dengan nilai interprestasi 3,09 berdasarkan pengujian ISO 9126.

\section{DAFTAR PUSTAKA}

[1] Tohari, Hamim. 2014. Astah : Analisis Serta Perancangan Sistem Informasi melalui pendekatan UML. Yogyakarta : Andi Offset

[2] Rosalina, Vidila. 2015. Pengujian Sistem Customer Relationship Management (CRM) Pada Perusahaan Petrokimia Menggunakan ISO/IEC 9126. Banten: Jurnal Sistem Informasi Vol. 2 
[3] Amanda Dwi P, Galang dkk. 2014. Pengukuran Kualitas untuk Aplikasi Permainan pada Perangkat Bergerak berdasarkan ISO 9126. Surabaya : Jurnal Institut Teknologi Sepuluh Nopember (ITS) ISSN 2085-4579 Vol. V No. 2

[4] S, Rosa A dan M. Shalahuddin. 2014. Rekayasa Perangkat Lunak Terstruktur dan Berorientasi Objek. Bandung : Informatika
[5] Irtanto. 2012. Efektivitas Sistem Manajemen Mutu ISO Terhadap Kualitas Pelayanan Administrasi Kependudukan di Kota Blitar. Jurnal Badan Penelitian dan Pengembangan Provinsi Jawa Timur

[6] Shadiqin, Rusyaidi. 2017. Pengujian Kualitas Perangkat Lunak Pada Faktor Reliability Menggunakan Standar ISO 9126. Yogyakarta : Skripsi Universitas Islam Indonesia 